\title{
Pharmacotherapy treatment of depression in patients with neurodegenerative diseases: where are we?
}

\section{Tratamento farmacológico da depressão em pacientes com doenças neurodegenerativas: onde nós estamos?}

\author{
Marcos Hortes N. Chagas, Lígia Horta de Macedo, José Alexandre S. Crippa
}

Department of Neuroscience and Behavior of the Ribeirão Preto Medical School, University of São Paulo (USP), INCT Translational Medicine (CNPq), São Paulo SP, Brazil. Correspondence: Marcos Hortes N. Chagas; Hospital das Clínicas da Faculdade de Medicina de Ribeirão Preto da USP;Avenida Bandeirantes 3.900 / $3^{\circ}$ andar; 14048-900 Ribeirão Preto SP - Brasil; E-mail:mchagas@fmrp.usp.br

Conflict of interest: There is no conflict of interest to declare.

Received 02 March 2012; Received in final form 16 March 2012; Accepted 23 March 2012

\section{Dear Editors,}

According to a Brazilian study in a population of over 65-years-old, the prevalence rate of Alzheimer's disease $(\mathrm{AD})$ is $3.9 \%^{1}$. It is well-known that depression is a common and disabling disorder in this population, but the advantage of antidepressant use for its treatment remains uncertain.

A recent study has evaluated the efficacy of sertraline and mirtazapine in the treatment of depression in patients with $\mathrm{AD}^{2}$. The authors evaluated 218 patients with depression divided into three groups (sertraline, mirtazapine, and placebo). No differences were found among the groups for the outcome response and remission of depression. This study was conducted with appropriate time (outcomes measured on 13 and 39 weeks) and doses. Adverse side effects were significantly greater in the group using antidepressants when compared to the placebo group. The authors concluded that it is needed to reconsider the use of antidepressants as first line treatment of depression in $\mathrm{AD}$.

Another neurodegenerative disease, Parkinson's disease (PD), affects approximately $3.3 \%$ of patients over 64 years ${ }^{3}$. Similarly, depression is highly prevalent in this population and may affect $25.5 \%$ of PD patients, according to a study conducted with a sample of a Brazilian tertiary hospital ${ }^{4}$. In general, antidepressants are used to treat depression in
$\mathrm{PD}$, however, a recent meta-analysis concluded that there is no sufficient evidence to indicate differences in rates of response or remission in depression in PD patients using selective ser otonin reuptake inhibitor antidepressants or placebo $^{5}$. The review also highlights that there are few clinical trials conducted so far and that in these studies the small samples sizes make definitive conclusions more difficult to reach.

It is also important to address that patients with depression and neurodegenerative diseases may not similarly respond to the antidepressants commonly used in patients without these neurological comorbidities.

The diagnosis of depression in $\mathrm{AD}$ and $\mathrm{PD}$ can be challenging, since some symptoms of these neurodegenerative diseases overlap depression symptoms. For instance, sleep and appetite disturbance, apathy and psychomotor retardation are prevalent in both conditions. Thus DSM-IV criteria could not be valid in these cases. Furthermore, pathophysiological mechanisms related to the emergence of depression in these diseases could be different or even part of the neurodegenerative process.

As noted above, many questions can be made from these findings and all of them evidence to the need of more research and a careful examination of the use of the antidepressant for the treatment of neurodegenerative diseases in clinical practice.

\section{References}

1. Herrera E Jr., Caramelli P, Silveira AS, Nutrini R. Epidemiologic survey of dementia in a community-dwelling Brazilian population. Alzheimer Dis Assoc Disord 2002;16:103-108.

2. Banerjee S, Hellier J, Dewey M, et al. Sertraline or mirtazapine for depression in dementia (HTA-SADD): a randomised, multicentre, double-blind, placebo-controlled trial. Lancet 2011;378:403-411.

3. Barbosa MT, Caramelli P, Maia DP, et al. Parkinsonism and Parkinson's disease in the elderly: a community-based survey in Brazil (the Bambui study). Mov Disord 2006;21:800-808.

4. Chagas MH, Crippa JA, Loureiro SR, et al. Validity of the PHQ-2 for the screening of major depression in Parkinson's disease: two questions and one important answer. Aging Ment Health 2011;15:838-843.

5. Skapinakis P, Bakola E, Salanti G, et al. Efficacy and acceptability of selective serotonin reuptake inhibitors for the treatment of depression in Parkinson's disease: a systematic review and meta-analysis of randomized controlled trials. BMC Neurol 2010;10:49. 